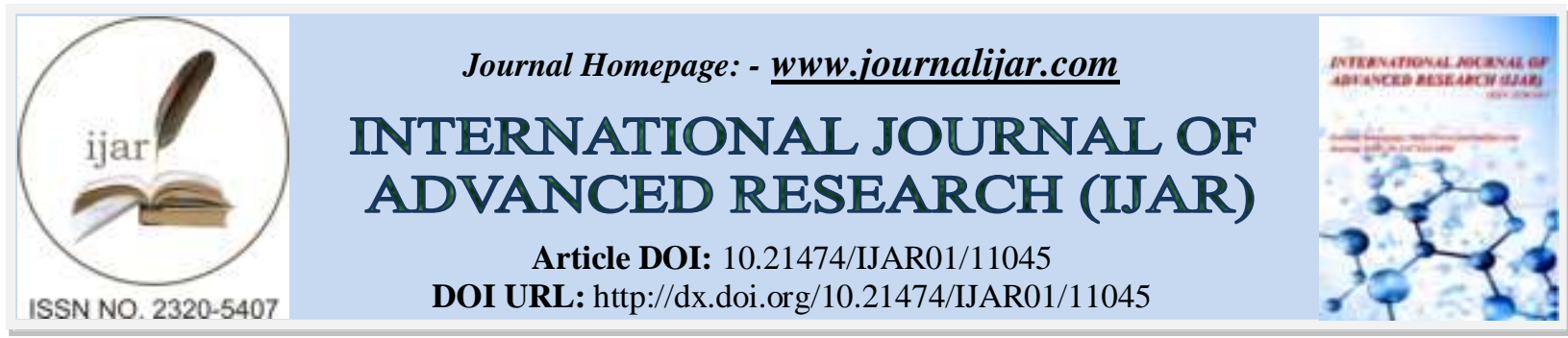

RESEARCH ARTICLE

\title{
THYROID STIMULATING HORMONE LEVELS AMONG NEWBORN AND ASSOCIATION WITH CONGENITAL HYPOTHYROIDISM IN A TERTIARY CARE HOSPITAL OF NORTH INDIA
}

\author{
Altaf Ahmad Bhat, Suhail Ahmad Naik, Farhana Mohd, Rukaya Akhter and Iqra Bhat Sheikh Mushtaq \\ Department of Pediatrics, GP Panth Children Hospital Lal Ded Maternity Hospital Srinagar.
}

\section{Manuscript Info}

Manuscript History

Received: 25 March 2020

Final Accepted: 30 April 2020

Published: May 2020

Key words:-

Newborn Screening, Incidence, Congenital Hypothyroidism, Screening TSH Levels

\section{Abstract}

Background: Newborn screening for hypothyroidism has been very valuable to detect hypothyroidism in neonatal period. And early thyroxin replacement has improved neurological development and physical growth of such babies. Screening for TSH early in neonatal life, the necessity of doing confirmatory tests is still unclear. $\mathrm{CH}$ is one of the most common preventable causes of intellectual disability [1]. Screening programs for $\mathrm{CH}$ have been developed in many countries Objectives: The study was done to find the incidence of congenital hypothyroidism as well as the association of congenital hypothyroidism with serum TSH levels (10-20mIU/L.)

Methods: In a prospective study, the various characteristics of the Newborn like birth weight, gender, gestational age and maternal thyroid status were recorded, stable newborn babies beyond 34 weeks of gestational age were screened for congenital hypothyroidism using venous TSH levels. Those with TSH levels $\geq 10 \mathrm{mIU} / \mathrm{L}$ were subjected to confirmatory free T4 and TSH levels test for diagnosis based on recommendations of the Indian Society for Pediatric and Adolescent Endocrinology (ISPAE). The association between screening TSH levels $10-20 \mathrm{mIU} / \mathrm{L}$ and congenital hypothyroidism was also studied.

Results: 3000 neonates were screened for congenital hypothyroidism. $350(11 \%)$ were retested with free T4 and Serum TSH levels. Out of 350 newborns 10 were diagnosed as case of $\mathrm{CH}$ and started on levo thyroxin Overall incidence of $\mathrm{CH}$ among screened babies was $0.3 \%$. There was significant association between screening TSH levels and congenital hypothyroidism. Two newborns $(0.06 \%)$ and $8(0.2 \%)$ newborns diagnosed with congenital hypothyroidism had screening TSH levels in the range of $10-20 \mathrm{mIU} / \mathrm{L}$ and $>20 \mathrm{mIU} / \mathrm{L}$ respectively, but this association was not found to be statistically significant. Combined Repeat TSH and Free T 4 was more accurate but costly.

Conclusion: Screening newborns for TSH levels and high index of suspicion when TSH is as low as $10 \mathrm{mIU} / \mathrm{L}$, recommending retest after 20 days of life to detect $\mathrm{CH}$ early in life and prevent treatable cause of mental retardation.

Copy Right, IJAR, 2020,. All rights reserved. 


\section{Introduction:-}

Newborn screening for hypothyroidism has been a major development in medical science. The first multi-centric study screening above 1 lakh neonates born throughout India was launched by Indian Council of Medical Research (ICMR) National Task Force Team on New Born Screening (NBS) at AIIMS New Delhi (2007-2012) and the preliminary results reveal a much higher incidence of $\mathrm{CH}$ all over India at 1 in 1172, particularly in south Indian population (1 in 727). Results have been released by ICMR team on March 15, 2013 presided by Tamil Nadu Government Deputy Director of Medical Education[3]. In another review by Sundararaman the result of the pilot study of the above project was quoted to be 1.6 in 1000[4]. Early diagnosis of congenital hypothyroidism is important because it is one of the most common preventable causes of mental retardation [5]. Most cases of congenital hypothyroidism are sporadic and occur in one in 3000 to 4000 infants [6]. Hypothyroidism in newborns is often overlooked as most of them with congenital hypothyroidism have normal appearance without any physical signs. This emphasizes the need for newborn screening for hypothyroidism [7]. $\mathrm{CH}$ includes subclinical $\mathrm{CH}$. However, there is a lack of consensus on the definition of subclinical $\mathrm{CH}$. $\mathrm{CH}$ is a generic term for congenital thyroid hormone deficiency due to a morphological abnormality or dysfunction of the thyroid gland that develops in the fetal or perinatal stage. Subclinical $\mathrm{CH}$ is also referred to as compensated hypothyroidism. Subclinical $\mathrm{CH}$ has no symptoms, i.e., it is a subclinical disease, but some patients may have a low thyroid hormone level [8]. Most of the newborn screening programs recommend to measure TSH levels initially followed by T4 levels if TSH levels are elevated. The screening program considers TSH levels to be elevated if it is $\geq 25 \mathrm{mIU} / \mathrm{L}$ for infants $<24$ hours of age, $>20 \mathrm{mIU} / \mathrm{L}$ for infants 24 to 96 hours of age and $\geq 15 \mathrm{mIU} / \mathrm{L}$ for infants $>96$ hours of age. The optimal time for screening is 48 to 72 hours of age. This is to minimize the false positive high TSH due to the physiological neonatal TSH surge that elevates TSH levels and causes dynamic T4 and T3 changes in the first 1 or 2 days after birth. Also for infants less than $1500 \mathrm{~g}$ birth weight, repeat specimens should be sent at 2, 6 and 10 weeks of age due to risk of delayed TSH elevation [9]. Many screening programs use TSH levels above 20-25mIU/L. Neonates TSH levels $>50 \mathrm{mIU} / \mathrm{L}$ are most likely to have permanent $\mathrm{CH}$, whereas a TSH level between $20-49 \mathrm{mIU} / \mathrm{L}$ is frequently a false positive or represents transient hypothyroidism [2]. In a survey of pediatric endocrinologists, infants with TSH $\geq$ $10 \mathrm{mIU} / \mathrm{L}$ at $<6 \mathrm{mo}$ after birth (excluding neonates) and those with $\mathrm{TSH} \geq 5 \mathrm{mIU} / \mathrm{L}$ at $12 \mathrm{mo}$ after birth were considered to have abnormalities and to require treatment [10]. Patients with slightly high TSH may subsequently be diagnosed with persistent $\mathrm{CH}$. Therefore, infants in such cases should be very carefully followed up from birth and an appropriate cut off point for early diagnosis and treatment for the cost effectiveness of the program. Also there no such study from Kashmir valley on the regional prevalence.

\section{Aims and Objectives:-}

1. To study the incidence of congenital hypothyroidism among newborns born in a tertiary care hospital in Kashmir valley.

2. To study the association of congenital hypothyroidism with screening TSH levels 10-20mIU/L.

\section{Materials And Methods:-}

After obtaining approval from the institutional ethics committee this hospital based prospective observational study conducted in the newborn unit of children hospital and Lal Ded Maternity Hospital, associated with GMC Srinagar, over a period of 24 months from October 2015 to October 2017. All Stable neonates beyond GA of 34 weeks were included. On the basis of Incidence of congenital hypothyroidism in a study among 1000 neonates conducted by ICMR, Sample size was calculated. Fixing 95\% confidence level and 20\% relative precision, the calculated sample size was 3000 . Venous blood was drawn from the babies after 48 hours of life. Serum TSH level were analyzed by chemi luminescent immunoassay. Babies with TSH levels above $10 \mathrm{mU} / \mathrm{L}$ were retested for free T4 and TSH levels at $7^{\text {th }}$ day of life and if TSH remains above $10 \mathrm{mIU} / \mathrm{L}$ babies were recalled after 21 days of age for repeat testing. Diagnosis was based on consensus guidelines of the Indian Society for Pediatric and Adolescent Endocrinology (ISPAE) [6]. If venous free T4 concentrations were below norms for age treatment was started immediately. If venous TSH levels were $\geq 15 \mathrm{mIU} / \mathrm{L}$ after 3 weeks of age, treatment was started even if free T4 concentrations were normal. If free T4 levels were low $(<1.1 \mathrm{ng} / \mathrm{dl})$ irrespective of TSH or if free T4 $<1.7 \mathrm{ng} / \mathrm{dl}$ with TSH $>20 \mathrm{mIU} / \mathrm{L}$ (TSH $>10 \mathrm{mIU} / \mathrm{L}$ for age $>2$ weeks), then also treatment was started immediately. The reference ranges (mean \pm SD) of free T4 and TSH levels for term and preterm infants at different ages of life are shown in Table 1.

Table 1:- Age wise reference range for thyroid function tests in neonatal age group.

\begin{tabular}{|llcc|}
\hline \multicolumn{2}{|c}{ Age } & Free T4(ng/dl) & TSH(mIU/L) \\
\hline Term neonates[11] & Cord & $1.07-2.02$ & $2.22-10.66$ \\
\hline
\end{tabular}




\begin{tabular}{|c|c|c|c|}
\hline & $1^{\text {st }}$ day & $1.2-2.6$ & $2.69-26.5$ \\
\hline & $3^{\text {rd }}$ day & $1.2-3.3$ & $2.8-18.6$ \\
\hline & $7^{\text {th }}$ day & $1.13-2.69$ & $1.34-12.08$ \\
\hline & $10^{\text {th }}$ day & $1.8-2.49$ & $1.18-10.72$ \\
\hline & $14^{\text {th }}$ day & $1.13-2.23$ & $1.72-7.87$ \\
\hline & $28^{\text {th }}$ day & $1.23-1.94$ & $2.02-4.9$ \\
\hline Preterm neonates[12] & $28-40$ weeks post conception age & $0.78-2.56$ & $0.82-12$ \\
\hline
\end{tabular}

The characteristics of newborn infants like birth weight, period of gestation, gender, maternal thyroid status and their relation with congenital hypothyroidism were studied. The association between congenital hypothyroidism and screening TSH levels were analyzed using Fischer's exact test and chi square test. A p value of $<0.05$ was considered significant.

\section{Results:-}

During the current study over a period of 24 months, 3000 newborn babies were screened for congenital hypothyroidism. 350 babies (11.6\%) with Serum TSH in range2 of 10 to 20 and above $\geq 20 \mathrm{mIU} / \mathrm{L}$ were retested with serum free T4 and TSH levels. 200 (57.1\%) of the retested neonates were males and 150(42.8\%) were females. Screening characteristics of retested neonates are presented in table 2.

Table 2:- Screening characteristics of the retested neonates.

\begin{tabular}{|c|c|}
\hline Variables & Number $(\%)$ \\
\hline \multicolumn{2}{|l|}{ Birth weight (gm) } \\
\hline$\geq 3000$ & 80 \\
\hline $2500-3000$ & 170 \\
\hline $2000-2500$ & 100 \\
\hline \multicolumn{2}{|l|}{ Gestational age(weeks) } \\
\hline Term $(\geq 38)$ & 55 \\
\hline $36-38$ & 250 \\
\hline $34-36$ & 45 \\
\hline \multicolumn{2}{|l|}{ Sex } \\
\hline 1.Male & 200 \\
\hline 2.Female & 150 \\
\hline \multicolumn{2}{|l|}{ Maternal thyroid Status } \\
\hline Normal & 345 \\
\hline Hypothyroidism & 5 \\
\hline hyperthyroidism & 0 \\
\hline
\end{tabular}

350 neonates were retested. The retest rate was $11.6 \%$ using a screening TSH cut-off of $\geq 10 \mathrm{mIU} / \mathrm{L}, 10$ were diagnosed $(2.8 \%)$ as congenital hypothyroidism and was started on treatment with Levo Thyroxine. There was significant association between screening TSH levels and congenital hypothyroidism (using Fisher's exact test, p <0.001). Incidence of congenital hypothyroidism in the present study is 0.33 (3.3 per 1000 live births) Among neonates with congenital hypothyroidism, 6(60\%) were males and 4(40\%) were females (male: female ratio 1.5:1). Of the $\mathrm{CH}$ cases 6 were full term $(60 \%)$ and $4(.40 \%)$ were preterm infants (34-36 weeks). There was no statistical association between birth weight or gestational age and maternal hypothyroidism. In 5 neonates (1.4\%) retested, mother had history of hypothyroidism and were on Thyroxine replacement therapy throughout pregnancy (more than $75 \mathrm{mcg} / \mathrm{day}$ ), there was no statistical association between $\mathrm{CH}$ and Maternal Hypothyroidism. The proportion of retested neonates diagnosed as $\mathrm{CH}$ based on screening TSH levels is given in table 3. 
Table 3:- Congenital hypothyroidism and screening TSH levels.

\begin{tabular}{|l|l|l|l|}
\hline Screening TSH & CH & No CH & Total \\
\hline $10-20 \mathrm{mIU} / \mathrm{L}$ & $2(0.57 \%)$ & $313(89.4 \%)$ & 315 \\
\hline$\geq 20 \mathrm{mIU} / \mathrm{L}$ & $8(2.2 \%)$ & $27(7.7 \%)$ & 35 \\
\hline Total & $10(2.8 \%)$ & $340(97.1 \%)$ & 350 \\
\hline
\end{tabular}

Of the 10 cases diagnosed as $\mathrm{CH}$, free T4 levels were low with TSH levels $>20 \mathrm{mIU} / \mathrm{L}$ in 8 cases. Normal FT4 and TSH $10-20 \mathrm{mIU} / \mathrm{L}$ was got in 2case and when retested after 21 days of age confirmed to have CH (low FT4 and TSH $>20 \mathrm{mIU} / \mathrm{L}$ ). The thyroid hormone levels of the cases diagnosed are shown in table 4.

Table 4:- Thyroid hormone profile in newborns with congenital hypothyroidism.

\begin{tabular}{|c|c|c|}
\hline Screening TSH & FT4(ng/dl), TSH(mIU/L) & $\begin{array}{l}\text { FT4 (ng/dl),TSH } \quad(\mathrm{mIU} / \mathrm{L}) \text { at } \\
\text { 21days }\end{array}$ \\
\hline \multicolumn{3}{|r|}{ Havo } \\
\hline 19.74 & 1.9 & 1.4, \\
\hline 15.6 & 1.19, & \\
\hline \multicolumn{3}{|l|}{$>20 \mathrm{mIU} / \mathrm{L}$} \\
\hline 26.7 & 25.06 & 1.11 \\
\hline 46.43 & 72.5 & \\
\hline 25 & 37.95 & 1.5, \\
\hline 28 & 1.6, & \\
\hline 80 & 1.01, & \\
\hline$>100$ & 0.96 & \\
\hline 25.6 & 1.03 & 45.9 \\
\hline 22 & 0.122, & \\
\hline
\end{tabular}

\section{Discussion:-}

This study was done to find out the incidence of congenital hypothyroidism among babies admitted in G B Panth children hospital and Lal Ded maternity hospital, Srinagar over a period of two years and to know if those babies with screening TSH between 10-20mIU/L need to be retested for diagnosing congenital hypothyroidism as against the conventional practice of retesting those with levels above $20 \mathrm{mIU} / \mathrm{L}$. The incidence of congenital hypothyroidism in the present study is 1 in 350 among newborn of Kashmir valley. Recent Indian data suggests a high incidence of congenital hypothyroidism which reports 1 in 2640 based on the study done by Desai et al. in 1998, 1 in 1985 from Hyderabad, 2.1 in 1000 from Kochi and 1 in 2221 in another study recently from U.P [13, 14, 15, 16 ]. Our study shows a high prevalence which implies better screening strategies and probably iodine deficiency in mothers which require further studies to make an authentic statement. The variable results among the studies could be due to the variation in sample sizes and the inclusion of preterm infants in some studies.

The female to male sex ratio of congenital hypothyroidism in the study was 1:1.5 and gender was not a significant risk factor for the occurrence of $\mathrm{CH}$. This is in line with a study from Iran reporting a female to male ratio of 1:1.4[17]. A recent meta analysis found a pooled female to male sex ratio of congenital hypothyroidism incidence of $1.35(95 \% \mathrm{CI}: 0.99,1.83)$ with a significant heterogeneity among studies and a higher risk in girl gender which is in sharp contrast to our study[18]. This difference may be due to small sample size in our study. We found no significant association between $\mathrm{CH}$ and other variables like birth weight, gestational age and maternal hypothyroidism. The study from Iran shows a similar picture [17].. This emphasizes the need for screening mothers also for hypothyroidism. We used the screening TSH cutoff of $10 \mathrm{mIU} / \mathrm{L}$ and 350 out of 3000 neonates $(11 \%)$ had to be retested. Of these $315(88.2 \%)$ had TSH $10-20 \mathrm{mIU} / \mathrm{L}$ and $42(11.8 \%)$ had TSH $\geq 20 \mathrm{mIU} / \mathrm{L}$. Of the 315 cases with screening TSH $10-20 \mathrm{mIU} / \mathrm{L}, 2$ cases $(0.6 \%)$ were subsequently diagnosed to have congenital hypothyroidism and there was no statistical correlation. In an Italian study a screening TSH cutoff of $<15 \mathrm{mIU} / \mathrm{L}$ was used and found that among those diagnosed with $\mathrm{CH}$ with screening TSH values below $15 \mathrm{mIU} / \mathrm{L}, 21.6 \%$ had permanent hypothyroidism and $54 \%$ had transient hypothyroidism[19]. In a study done in preterm infants $<35$ weeks a lower cutoff of $6 \mathrm{mIU} / \mathrm{L}$ was used and concluded that using such a lower cut off in preterm infants could diagnose $\mathrm{CH}$ earlier and avoid repeat testing at 36 weeks since they usually exhibit a delayed TSH rise[20]. A study by ICMR task force in infants 34 weeks and above recommends that $10 \mathrm{mIU} / \mathrm{L}$ is the 97.5 th percentile value even when corrected for gender, birth weight and age at sampling and thus $10 \mathrm{mIU} / \mathrm{L}$ seems to be the right cutoff beyond which 
a second sample should be sought [21]. This study reinforces the fact that congenital hypothyroidism is highly prevalent in our population especially this Himalayan region and meticulous screening is needed to pick up the cases. Though we don't have studies correlating lower screening TSH levels and congenital hypothyroidism. In the present study also although only 2 cases with screening TSH $<20 \mathrm{mIU} / \mathrm{L}$ turned out to be $\mathrm{CH}$ without any statistical significance, given the gravity of $\mathrm{CH}$ and its consequences, we strongly recommend to recall newborns for thyroid function tests if screening TSH levels are above $10 \mathrm{mIU} / \mathrm{L}$. The main limitation of our study was sample size. A larger sample size would have been needed to get a statistical correlation between TSH levels $10-20 \mathrm{mIU} / \mathrm{L}$ and $\mathrm{CH}$. Further studies on a larger population are necessary to eliminate other factors.. Another limitation was that we didn't categorize into preterm and terms and preterm less than 34 were excluded which may be the reason for the heterogeneity in the incidence of $\mathrm{CH}$ when compared to other Indian studies.

\section{Conclusion:-}

The high incidence of congenital hypothyroidism in this study corroborates the need for universal screening of newborns. The occurrence of $\mathrm{CH}$ in babies with screening TSH levels $10-20 \mathrm{mIU} / \mathrm{L}$ though in a smaller proportion raises the question whether the cutoff of screening TSH should be brought down to a lower level. More studies on a larger sample are needed to hit upon a solution.

\section{What this study adds:}

Incidence congenital hypothyroidism in this region is significant, we stress on the need of researches on etiologies of congenital hypothyroidism like genetic factors etc. and recommend TSH screening of all newborn babies for $\mathrm{CH}$, followed by confirmatory thyroid function tests in newborns with higher screening TSH levels.

\section{Funding:}

None

\section{Conflict of interest:}

None

\section{Abbreviations:}

TSH- thyroid stimulating hormone, $\mathrm{CH}$ - congenital hypothyroidism

\section{References:-}

1. Harris KB, Pass KA. Increase in congenital hypothyroidism in New York State and in the United States. Mol Genet Metab. 2007;91:268.

2. Cao XY, Jiang XM, Dou ZH, Rakeman MA, Zhang ML, O'Donnell K. Timing of vulnerability of the

3. brain to iodine deficiency in endemic cretinism. N Engl J Med. 1994;331:1739-44

4. ICMR Releases Results of Study on Congenital Hypothyroidism. Chennaionline News. Mht. 2013. Mar 15, [Last accessed on $2015 \mathrm{Feb} 05$ ]

5. Sundararaman PG. Neonatal thyroid dysfunctions lessons from Indian exprerience. Thyroid Res Pract. 2013;10:S1

6. Ayyad AH, Hashemipour M, Hovsepian S, Kooshki AM, Afshari M. The relation between serum and filter paper TSH level in neonates with congenital hypothyroidism. Adv Biomed Res 2014;3:23

7. Büyükgebiz A. Newborn screening for congenital hypothyroidism. Journal of clinical research in pediatric endocrinology. 2013 Mar; 5(Suppl 1):8.

8. Büyükgebiz A. Congenital hypothyroidism clinical aspects and late consequences. Pediatric endocrinology reviews: PER. 2003 Dec; 1:185-90.

9. Ishii T, Anzo M, Adachi M, Onigata K, Kusuda S, Nagasaki K. Mass Screening Committee Japanese Society for Pediatric Endocrinology Japanese Society for Mass Screening. Guidelines for diagnosis and treatment of 21hydroxylase deficiency (2014 revision). Clin Pediatr Endocrinol. 2015; 24:77-105.

10. Eichenwald EC, Martin C, Stark AR. CLoherty and Stark's Manual of neonatal care. Wolters Kluwer; 2017

11. Desai MP, Sharma R, Riaz I, Sudhanshu S, Parikh R, Bhatia V. Newborn screening guidelines for congenital hypothyroidism in India: recommendations of the Indian Society for Pediatric and Adolescent Endocrinology (ISPAE)-Part I: Screening and confirmation of diagnosis. The Indian Journal of Pediatrics. 2018 Jun 1;85(6):440-7. 
12. Mutlu M, Karagüzel G, AlİyazicioĞlu Y, EyüpoĞlu İ, Ökten A, Aslan Y. Reference intervals for thyrotropin and thyroid hormones and ultrasonographic thyroid volume during the neonatal period. The Journal of Maternal-Fetal \& Neonatal Medicine. 2012 Feb 1;25(2):120-4.

13. Clark SJ, Deming DD, Emery JR, Adams LM, Carlton EI, Nelson JC. Reference ranges for thyroid function tests in premature infants beyond the first week of life. Journal of Perinatology. 2001 Dec;21(8):531.

14. Gupta A, Srivastava S, Bhatnagar A. Cord blood thyroid stimulating hormone level-interpretation in light of perinatal factors. Indian pediatrics. 2014 Jan 1;51(1):32-6.

15. Sahai I, Zytkowicz T, Kotthuri SR, Kotthuri AL, Eaton RB, Akella RR. Neonatal screening for inborn errors of metabolism using tandem mass spectrometry: experience of the pilot study in Andhra Pradesh, India. The Indian Journal of Pediatrics. 2011 Aug 1;78(8):953-60.

16. Kapoor S, Gupta N, Kabra M. National newborn screening program-Still a hype or a hope now?. Indian pediatrics. $2013 \mathrm{Jull}$ 1;50(7):639-43.

17. Gopalakrishnan V, Joshi K, Phadke S, Dabadghao P, Agarwal M, Das V, et al. Newborn screening for congenital hypothyroidism, galactosemia and biotinidase deficiency in Uttar Pradesh, India. Indian pediatrics. 2014 Sep 1;51(9):701-5.

18. Prabhu S, Mahadevan S, Jagadeesh S, Suresh S. Congenital hypothyroidism: recent Indian data. Indian journal of endocrinology and metabolism. 2015 May 1;19(3).

19. Zeinalzadeh AH, Talebi M. Neonatal screening for congenital hypothyroidism in East Azerbaijan, Iran: the first report. Journal of medical screening. 2012 Sep;19(3):123-6.

20. Rezaeian S, Khazaei S, Hooshmand E, Esmailnasab N. Gender and risk of congenital hypothyroidism: A systematic review and meta-analysis. International Journal of Pediatrics. 2017;5(12):6703-12.

21. Olivieri A, Corbetta C, Weber G, Vigone MC, Fazzini C, Medda E, Italian Study Group for Congenital Hypothyroidism. Congenital hypothyroidism due to defects of thyroid development and mild increase of TSH at screening: data from the Italian National Registry of infants with congenital hypothyroidism. The Journal of Clinical Endocrinology \& Metabolism. 2013 Apr 1;98(4):1403-8.

22. Korada M, Pearce MS, Platt MW, Avis E, Turner S, Wastell H, Cheetham T. Repeat testing for congenital hypothyroidism in preterm infants is unnecessary with an appropriate thyroid stimulating hormone threshold. Archives of Disease in Childhood-Fetal and Neonatal Edition. 2008 Jul 1;93(4):F286-8. 